\title{
Stimulus recognizability judgments as a function of the utility of physical dimensions in recognition-discrimination problems'
}

\author{
G. ALFRED FORSYTH, UNIVERSITY OF NEW HAMPSHIRE \\ DONALD R. BROWN, PURDUE UNIVERSITY
}

The effect of different pretraining conditions on the scaling of random forms for recognizability was examined. Pretraining conditions were defined by exposure to recognition-discrimination problems structured to emphasize or de-emphasize metron variability. Analyses of the results of the scaling task indicated that exposure to problems designed to emphasize metron variability within the "compactness" and "jaggedness" physical dimensions resulted in more extensive use of those dimensions, while no similar effect resulted from training with problems emphasizing an "x-axis areal asymmetry" physical dimension

The importance of considering stimulus characteristics or physical dimensions of stimuli as determinants of response-centered scaling data has been discussed by Stevens (1951, p. 32), Attneave (1957), Gibson (1963), Kaswan et al (1965), and Stenson (1966). However, the lack of a complete physical quantification of any complex stimulus domain has prevented the identification of these determinants and the variables which lead to alterations in the use of specific physical dimensions. The physical dimensions referred to herein should be differentiated from the physical measures used in previous studies of stimulus correlates of perceptual behavior such as those by Attneave (1957), Polidora (1965), Zusne (1965), and Webster (1966). The measures refer to specific physical operations on the stimulus such as the moments of area or perimeter, while dimensions refer to clusters of similar physical measures. The problems associated with the quantification of stimulus domains and one attempt at such a quantification with a stimulus domain of random polygons has been presented by Brown and Owen (1967). Using this physical quantification, Forsyth and Brown (1967) presented evidence supporting a perceptual selective attention process, where a tachistoscopic procedure was used to determine the degree to which specific physical dimensions were used in selective perceptual attention.

In the present study a variation on an individual differences model (Tucker \& Messick, 1963) was used to determine whether tachistoscopic training, designed to emphasize the usefulness of specific physical dimensions, would result in a greater utilization of the emphasized dimensions when time permits the selection and use of addition dimensions beyond those used under tachistoscopic conditions. More specifically, it was hypothesized that after having been exposed to recognition-discrimination problems structured to emphasize differences in metron variability (Garner, 1962) within a specific physical dimension, Ss would make use of that dimension when scaling forms for recognizability under nontachistoscopic conditions.

\section{Subjects}

\section{METHOD}

Two hundred seventy-nine undergraduates at Purdue University served as Ss in this experiment.

\section{Stimuli and Problems}

The stimulus domain from which forms were selected was defined by Attneave and Arnoult's Method I (1956). The physical quantification of this domain has been described in detail by Brown and Owen (1967). For the scaling task, three sets of 15 forms each were selected with five forms with high, low, and intermediate ranks for Dimension 1 (compactness), Dimension 2 (jaggedness), and Dimension 3 ( $x$-axis areal symmetry), respectively. The definition of a form as high or low in rank on a given dimension was based upon the rank ordering of factor scores of 200 forms on each physical dimension. Figure 1 illustrates examples of high and low ranking forms on each of the three dimensions.

Forms for the recognition-discrimination problems were selected from the same stimulus domain and were used in a previous study (Forsyth \& Brown, 1967). A single problem consisted of two pictures, one a single form and the second that same form paired with one other form. Problems designed to emphasize metron variability on a selected dimension were constructed so that the paired picture consisted of one form with a high ranking factor score and the other with a low ranking factor score on the dimension under consideration. Similarly, the paired picture consisted of two forms with high ranking factor scores on problems constructed to de-emphasize metron variability on a specific dimension. Five problems of each type were constructed for each of the three dimensions.

\section{Apparafus and Procedure}

A three-channel tachistoscope (Scientific Proto- 
RANK
HIGH
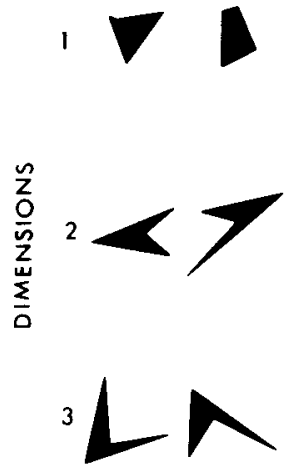

LOW
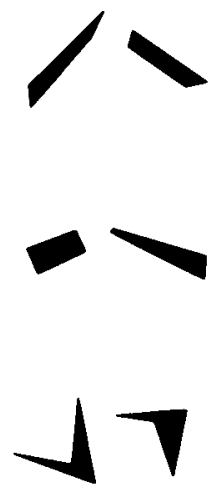

Fig. 1. Examples of high and low ranking forms on the "compactness" " "jaggedness", and "x-axis areal asymmetry" physical dimensions.

type Model GB) and its programming unit were used to present the recognition-discrimination training problems. Subjects receiving training on the problems before scaling were given 100 trials, where a single trial consisted of presenting a single form for durations of $4,8,12,16$, or $20 \mathrm{msec}$ in field 1 , then a blank interval for $300 \mathrm{msec}$ in field 2, followed by the presentation of two forms in field 3 of the tachistoscope. The 100 trials consisted of four exposures to each of five problems at each of the five durations. On each trial, $S$ was instructed to respond with the side on which the previously shown form appeared. If $S$ did not know which form appeared alone, the response "no"' was to be given. The order of presentation was randomized for each $\mathrm{S}$ with the restriction that the same problem never succeeded itself.

Nine groups of Ss were assigned to nine conditions based upon the factorial combination of the three sets of forms (selected on the basis of compactness, jaggedness, and $x$-axis areal asymmetry) and three conditions of previous experience with recognitiondiscrimination problems (emphasis of metron variability on a selected dimension, de-emphasis of metron variability on a selected dimension, and no exposure to recognition-discrimination problems). Twenty-six Ss from each set were given recognitiondiscrimination problems consisting of stimuli ranking high paired with stimuli ranking low on a given dimension, another 26 Ss from each set were given problems consisting of stimuli ranking high paired with stimuli also ranking high on the specified dimension, and the remaining $\mathrm{Ss}$ in each set received no exposure to stimuli. The dimension under consideration for Data Sets 1,2, and 3 were compactness, jaggedness, and $x$-axis areal asymmetry, respectively.

In the scaling task, $S$ was shown the 15 forms appropriate to the set to which he belonged. The forms were displayed in a random order on a large table. While $\mathrm{S}$ was examining the forms he was asked to assume that he would later be required to find the 15 forms imbedded in a display of 100 forms. $S$ was instructed to place the symbol representing the form he thought he would find first in such a display above the number " 1 " on the table and consider that form as easiest to recognize, then to successively select the next easiest to recognize, until he had placed the symbol representing the form he considered most difficult to recognize above the number "15."

\section{RESULTS}

The scaling task results for each of the three sets of forms were separately analyzed. The data matrices consisted of the rank assigned to each form by each $\mathrm{S}$, and were of dimensions 95 by 15, 94 by 15 , and 89 by 15 for Sets 1,2 , and 3, respectively.

The analysis for each of the three sets of data involved: (1) factor analyzing the data to obtain a rotated factor matrix with loadings on forms (U); (2) obtaining the rotated factor matrix with loadings of Ss (W) from U; (3) selecting Ss having high loadings on each rotated factor and testing to find if more Ss than would be expected by chance came from each of the three groups comprising a set of data; and (4) examining which of 12 physical dimension-produced rankings of forms correlated highly with Ss having high loadings on a given rotated response factor.

Tucker and Messick (1963) recommend that when the number of Ss exceeds the number of stimuli or stimulus pairs (in this case the ranks on 15 forms), the factor analysis should be computed on correlations between stimuli rather than individuals. This approach was taken in factor analyzing the rank-order correlation matrix for each set of data to obtain a matrix $U$ which is the rotated factor matrix having elements which represent projections of points corresponding to forms. The principal component solution was used and an orthogonal rotation performed on the factor matrix. The rotation was accomplished on the first four factors for each set of data, where the criteria for selecting the number of factors were eigen values greater than 1.0 and interpretability. Table 1 presents the cumulative proportions of total variance accounted for by each factor for each set of data.

Table 1. Cumulative proportions of total variance accounted for by the first four factors for Data Sets 1,2 , and 3

\begin{tabular}{lllll} 
& & & Set & \\
& & 1 & 2 & 3 \\
\hline \multirow{4}{*}{ Factor } & 1 & .36 & .50 & .36 \\
& 2 & .60 & .63 & .48 \\
& 3 & .61 & .72 & .56 \\
& 4 & .68 & .77 & .65 \\
\hline
\end{tabular}


Table 2. Number of Ss from Groups 1, 2, and 3 of Set 1 attaining the highest 20 positive or negative loadings on rotated factors, range of each set of 20 loadings, expected frequencies, and chi square values for each row of the table.

\begin{tabular}{|c|c|c|c|c|c|}
\hline \multirow[t]{2}{*}{ Factor } & \multicolumn{3}{|c|}{ Group } & \multirow[b]{2}{*}{ Range of Loadings } & \multirow[b]{2}{*}{ Chi Square } \\
\hline & 1 & 2 & 3 & & \\
\hline Factor 1- & 15 & 2 & 3 & -6.17 to -7.36 & $22.82 *$ \\
\hline Factor $1+$ & 2 & 6 & 12 & 3.15 to 6.10 & 3.20 \\
\hline Factor 2- & 1 & 4 & 15 & -7.18 to -10.23 & 7.94 \\
\hline Factor 3- & 2 & 5 & 13 & -4.51 to -11.10 & 3.95 \\
\hline Factor 4- & 4 & 5 & 11 & -1.00 to -9.59 & 0.86 \\
\hline $\begin{array}{l}\text { Factor } 4+ \\
\text { Expected }\end{array}$ & $\begin{array}{c}4 \\
5.47\end{array}$ & $\begin{array}{c}10 \\
5.47\end{array}$ & $\begin{array}{c}6 \\
9.06\end{array}$ & 7.54 to 11.75 & 5.18 \\
\hline
\end{tabular}

* Chi Square significant at the .001 level.

Because the relationship $\hat{\mathrm{X}}=\mathrm{UTW}$ exists, where $\hat{\mathrm{X}}$ is a least-squares approximation of $X$ (the original data matrix), $U$ is a matrix of rotated factors with loadings on forms, $T$ is a diagonal matrix of latent roots, and $W$ is a matrix of loadings of subjects on the rotated factors, it is possible to obtain $W$. The matrix $U$ is orthonormal so $\mathrm{W}=\mathrm{T}^{-1} \mathrm{U}^{\prime} \mathrm{X}$. This multiplication was performed and the resulting matrices were examined for high positive and negative loadings on each rotated factor for Sets 1,2, and 3. Subjects sharing similar loadings on a given response factor were assumed to be sharing a common point of view. Tables 2, 3, and 4 present the number of Ss from each prescaling condition which was among the highest 20 positive or the highest 20 negative loadings for each rotated factor, the range of the positive and negative loadings for each 20 Ss selected, and the distribution of Ss expected by chance on each point of view for Data Sets 1, 2, and 3, respectively. Also included in each of the three tables are the chi square tests on each distribution of $20 \mathrm{Ss}$. The high-loading positive or highloading negative distribution of $\mathrm{Ss}$ is not given in Tables 2, 3, and 4 for rotated factors if the loadings were near zero. In each table, Group 1 represents Ss exposed to problems designed to emphasize differences on the dimension under consideration, Group 2 represents Ss exposed to problems designed to deemphasize differences on the dimension under consideration, and Group 3 represents Ss receiving no exposure to the problems.

The chi square tests indicated that the prior expurience with the forms altered the distribution of Ss from what would be expected by chance in the case of the high negative loadings on rotated Factor 1 of Set 1 and the high negative loadings on rotated Factor 1 of Set 2. Specifically, more Ss previously exposed to problems designed to emphasize differences in "compactness" had higher negative loadings on Factor 1 of Set 1 than would be expected by chance, and more Ss previously exposed to problems designed to emphasize differences on the "jaggedness" dimension had higher negative loadings on Factor 1 of Set 2 than would be expected by chance. None of the chi square tests was significant for the set 3 data, indicating that the prior experience with the problems emphasizing or de-emphasizing differences on the " $x$-axis areal asymmetry" dimension did not differentially alter the points of view of Ss in this study.

For each set of data, the rank-order correlations of the rankings produced by each of the 20 Ss sharing a common point of view with rankings of the 15 forms on the basis of 12 physical dimensions were examined to reach some determination of physical dimensions relevanit to each point of view.

The first point of view (Factor 1-) for the Set 1 data corresponded most closely (median rho $=+.82$ ) to the compactness physical dimension, which was the dimension upon which differences were emphasized for 15 of the 20 Ss sharing that point of view. Similarly, the first point of view (Factor 1-) for the Set 2 data corresponded most closely (median rho= +.84 ) to the jaggedness physical dimension which was the dimension upon which differences were emphasized for 11 of the $20 \mathrm{Ss}$ sharing that point of view. No correspondence was found between the Set 3 points of view and the $\mathrm{x}$-axis areal asymmetry dimension. The highest median rho between the points of view and this dimension was .26 .

Because the physical dimensions were not orthogonal with respect to the samples of stimuli used, an examination of patterns for each point of view as suggested by Silver et al (1966) would have been somewhat misleading.

\section{DISCUSSION}

The data from this study indicate that previous exposure to problems designed to emphasize metron variability of one specific physical dimension of a stimulus domain will affect an individual's point of view with regard to recognizability when time is available to search for and use many different characteristics to scale stimuli. The present results are consistent with the demonstration by Munsinger and Kessen (1964) that the Type A scaling (Coombs, 1964) of stimuli can be altered by the appropriate training. The

Table 3. Number of Ss from Groups 1, 2, and 3 of Set 2 attaining the highest 20 positive and negative loadings on rotated factors, range of each set of 20 loadings, expected frequencies, and chi square values for each row of the table.

\begin{tabular}{|c|c|c|c|c|c|}
\hline \multirow[t]{2}{*}{ Factor } & \multicolumn{3}{|c|}{ Group } & \multirow[b]{2}{*}{ Range of Loadings } & \multirow[b]{2}{*}{ Chi Square } \\
\hline & 1 & 2 & 3 & & \\
\hline Factor 1- & 11 & 7 & 2 & -4.33 to -4.85 & $11.17^{*}$ \\
\hline Factor I+ & 1 & 4 & 15 & 3.85 to 5.30 & 8.25 \\
\hline Factor 2- & 10 & 7 & 3 & -3.51 to -6.53 & 7.94 \\
\hline Foctor 2+ & 2 & 4 & 14 & 11.57 to 14.71 & 5.55 \\
\hline Factor 3- & 4 & 6 & 10 & -8.30 to -12.47 & 0.59 \\
\hline Factor 4- & 9 & 7 & 4 & -11.31 to -17.26 & 5.29 \\
\hline Factor 4+ & 3 & 6 & 11 & 26.72 to 35.40 & 1.68 \\
\hline Expected & 5.532 & 5.532 & 8.936 & & \\
\hline
\end{tabular}

* Chi Square significant at the .01 level. 
Table 4. Number of Ss from Groups 1, 2, and 3 of Set 3 attaining the highest 20 positive and negative loadings on rotated factors range of each set of 20 loadings, expected frequencies, and chi square values for each row of the table.

\begin{tabular}{|c|c|c|c|c|c|}
\hline \multirow[t]{2}{*}{ Factor } & \multicolumn{3}{|c|}{ Group } & \multirow[b]{2}{*}{ Range of Loodings } & \multirow[b]{2}{*}{ Chi Square } \\
\hline & 1 & 2 & 3 & & \\
\hline Factor 1+ & 7 & 7 & 6 & 4.22 to 4.46 & 1.23 \\
\hline Factor 2- & 5 & 6 & 9 & -9.19 to -11.51 & 0.15 \\
\hline Factor 3+ & 5 & 4 & 11 & 7.85 to 12.31 & 1.42 \\
\hline Factor 4- & 9 & 2 & 9 & -4.71 to -7.66 & 4.31 \\
\hline Factor $4+$ & 2 & 9 & 9 & 2.03 to 14.20 & 4.31 \\
\hline Expected & 5.778 & 5.778 & 8.444 & & \\
\hline
\end{tabular}

results also compare favorably with those by Forsyth and Brown (1967). Both compactness and jaggedness appear to be high enough in the hierarchical order of physical dimensions to which Ss attend that their usefulness can be manipulated, while the $x$-axis areal asymmetry appears to be low enough in that hierarchy that it was not a useful one in this experiment. Whether this and other dimensions can be made useful in other experimental situations, and what person and environmental variables are relevant in determining an S's point of view are questions for future research.

The distribution of Ss from any given experimental group in all three sets of data strongly supports the use of the Tucker and Messick (1963) type of procedure for individual differences analysis rather than the more typical method of obtaining an "average individual" in a group to permit comparisons of diverse groups that are hypothesized to have different points of view or cognitive structures. If, in the present study, Ss exposed to problems designed to emphasize differences on a given pinysical dimension had been blended together to derive an average point of view for the group, the ranking of forms by Ss having high positive and negative loadings on different response factors would have been combined. It can be noted in Table 2, for example, that Set 1 Ss exposed to problems designed to emphasize differences on Dimension 1 comprised 15 of the 20 highest negative loadings on the first point of view. However, two Ss from that same experimental group were among the highest $20 \mathrm{Ss}$ having positive loadings on the first response factor and others were included in the highest 20 negative or positive loadings on other response factors. The implication for future research is that the study of variables which are hypothesized to influence points of view or cognitive structures would require a description of the point of view for each individual before the introduction of the environmental variable being studied.

\section{References}

Attneave, F., \& Amoult, M. D. The quantitative study of shape and pattern perception. Psychol. Bull., 1956, 53, 452-471.

Attneave, F. Physical determinants of the judged complexity of shapes. J. exp. Psychol., 1957, 53, 221-227.

Brown, D. R., \& Owen, D. H. The metrics of visual form: methodological dyspepsia. Psychol, Bull, 1967, 68, 243-259.

Coombs, C. H. A theory of data. New York: John Wiley \& Sons, 1964

Forsyth, G. A., \& Brown, D. R. Stimulus correlates of tachistoscopic discrimination-recognition performance: compactness, jaggedness, and areal asymmetry. Submitted to Percept. \& Psychophys., 1967.

Garner, W. R. Uncertainty and structure as psychological concepts. New York: John Wiley \& Sons, 1962.

Gibson, J. J. The useful dimensions of sensitivity. Amer. Psychol., $1963,18,1-15$

Kaswan, J., Young, S., \& Nakamura, C. Y. Stimuius determinants of choice behavior in visual pattern discrimination. $J$. exp. Psychol., 1965, 69, 441-449.

Munsinger, H., \& Kessen, W. Uncertainty, structure, and preference Psychol. Monogr., 1964, 78, 586

Polidora, V. J. Stimulus correlates of visual pattern discrimination by humans: area and contour. J.exp. Psychol., 1965, 69, 221223

Silver, C. A., Landis, D., \& Messick, S. Multidimensional analysis of form: an analysis of individual differences. Amer. J. Psychol. $1966,79,62-72$.

Stenson, H. H. The physical factor structure of random forms and their judged complexity. Percept. \& Psychophys.. 1966, 1, 303310 .

Stevens, S. S. Mathematics, measurement, and psychophysics. In S. S. Stevens (Ed.), Handbook of experimental psychology. New York: John Wiley \& Sons, 1951. Pp. 1-49.

Tucker, L. R., \& Messick, S. An individual differences model for multidimensional scaling. Psychometrika, 1963, 28, 333-367.

Webster, R. B. Stimulus characteristics and effects of fill, distortion, and noise on pattern perception. Percept. mot. Skills, 1966 , $23,19-33$

Zusne, L. Moments of area and of the perimeter of visual form as predictors of discrimination performance. J. exp. Psychol. $1965,69,213-220$

\section{Note}

1. This research was supported by Research Grant HD-00909 from the National Institute of Child Health and Human Development.

(Accepted for publication October 10, 1967.) 